Personalidade Acadêmica Homenageada:

Raymundo Juliano Feitosa (Universidade Federal do Rio Grande do Norte - UFRN)

\title{
O ESTADO NO PAPEL DESENVOLVIMENTISTA QUANDO DA TUTELA DOS CONTRATOS DE TECNOLOGIA E KNOW-HOW
}

\section{THE DEVELOPMENTALISM FUNCTION OF THE STATE IN THE AEGIS OF TECHNOLOGY AND KNOW-HOW TRANSFER}

\section{AGREEMENT}

CAMILA PADIN

Doutoranda e Mestre em Direito Político e Econômico pela Universidade Presbiteriana Mackenzie. Pesquisadora do Grupo de Pesquisa "Estado e Economia no Brasil" e do Projeto de Pesquisa "A aparente colisão entre direitos sociais e econômicos" ambos ligado ao Programa de Pós-Graduação stricto sensu em Direito Político e Econômico da Universidade Presbiteriana Mackenzie. Professora convidada nos cursos de PósGraduação presencial lato sensu em Direito Civil e Processo Civil, bem como Professora convidada nos cursos de Pós-Graduação lato sensu na modalidade EAD em Direito Civil e Processo Civil ambos na Universidade Presbiteriana Mackenzie. É também Professora convidada de Direito Constitucional e Direito Econômico Contemporâneo nos cursos EAD da BN2 Inteligência Educacional e Professora convidada da Escola Superior do Ministério Público de São Paulo no curso de Fundamentos e Metodologia da Pesquisa em Direito na modalidade EAD.

\section{FELIPE CHIARELLO DE SOUZA PINTO}

Coordenador Adjunto de Programas Acadêmicos da Área de Direito da CAPES-MEC. Bolsista Produtividade 2 do CNPq - Brasil (Processo n. 311353/2018-5). Mestre e doutor em Direito pela Pontifícia Universidade Católica de São Paulo, foi membro do Conselho Técnico Científico, do Conselho Superior e do Comitê da Área do Direito da CAPES-MEC. Atualmente é Diretor da Faculdade de Direito da Universidade Presbiteriana Mackenzie e Professor do Programa de Mestrado e Doutorado em Direito Político e Econômico, Professor colaborador do Programa de Pós-graduação em Direito da Universidade de Passo Fundo, Membro do Comitê da Área do Direito 
Personalidade Acadêmica Homenageada:

Raymundo Juliano Feitosa (Universidade Federal do Rio Grande do Norte - UFRN)

no Programa SciELO/ FAPESP, membro Titular da Academia Paulista de Letras Jurídicas e da Academia Mackenzista de Letras.

\section{LARISSA DIAS PUERTA DOS SANTOS}

Doutoranda em Direito Político e Econômico pela Universidade Presbiteriana Mackenzie em regime de cotutela com a Universidade de Salamanca (2017/atual); Mestre em Direito Político e Econômico pela Universidade Presbiteriana Mackenzie (2015/2017), Especialista em Direito Público pela Escola Superior do Ministério Público do Estado de São Paulo (2012/2015) e bacharel em Direito pela Universidade Presbiteriana Mackenzie (2007/2011). É membro do Grupo de Pesquisa Estado e Economia no Brasil ligado ao Programa de Pós-Graduação em Direito Político e Econômico. Advogada em São Paulo.e-mail: larissa.puerta@usal.es

\section{RESUMO}

O presente artigo propõe uma análise dos contratos de transferência de tecnologia sob ótica do cenário desenvolvimentista brasileiro Com as ideias apresentadas, pretende-se compreender a aplicação dos ideais desenvolvimentistas na construção do desenvolvimento tecnológico brasileiro tendo em vista que o governo deve ser incentivado a assumir uma robusta postura de fomentador do desenvolvimento interno sem, contudo, reprimir a liberdade de contratar conferida aos particulares no que se refere aos contratos envolvendo tecnologia. A ideia desenvolvida pode facilmente ser adotada no Brasil, e as razões para isso podem ser vislumbradas nesse ensaio que se propôs a trazer uma abordagem inicial da necessidade de uma postura arrojada do governo brasileiro no desenvolvimento tecnológico em meio ao cenário de crise atual.

PALAVRAS-CHAVE: Fomento Público; Investimento Estatal; Transferência de Tecnologia; Know-How. 
Personalidade Acadêmica Homenageada:

Raymundo Juliano Feitosa (Universidade Federal do Rio Grande do Norte - UFRN)

\section{ABSTRACT}

This paper proposes a analysis the Technology Transfer Agreement under the perspective of the Brazil's developmentalism landscape. With the ideas presented, the goal is to understand the application of the developmentalism ideals on the construction of the Brazilian technological development considering that the state must be stimulated to take a mature attitude of nurturer of internal development, without repressing the freedom of contract granted to the private individual regarding agreements involving technology. The presented idea can easily be adopted in Brazil, and the reason for that may be seen in this essay, that intends to bring a first approach on the necessity of a bolder posture from the Brazilian State on the technological development while in the middle of the current crisis scenario.

KEYWORDS: Public Fomentation; State Investment; Transfer of Technology; KnowHow.

\section{INTRODUÇÃO}

No atual processo de desenvolvimento e globalização, a proteção da tecnologia é de fundamental importância para salvaguardar as descobertas tecnológicas realizadas. Ao longo do processo evolutivo econômico, o homem tem se deparado com diferentes sistemas técnicos, sendo a inovação tecnológica um dos pilares do avanço cientifico contemporâneo traduzido no dia-a-dia pela automação industrial, meios de transporte, aprimoramento das tecnologias da informação que tem por maior objetivo romper com o sistema técnico anterior.

Esse ciclo produtivo retroalimentável é o que impulsiona grandes potências econômicas a estimularem a produção tecnológica, a inovação, a sustentabilidade para assim estarem sempre na vanguarda das demais potências.

Com a progressão do fluxo de tecnologia, considerando principalmente a expansão dos mercados em razão do comércio internacional e da integração econômica mundial, as transações jurídicas relacionadas à novas tecnologias 


\section{Personalidade Acadêmica Homenageada:}

Raymundo Juliano Feitosa (Universidade Federal do Rio Grande do Norte - UFRN)

aumentaram significativamente. Nessa trilha, os contratos são instrumentos essenciais no ato de formalização da transmissão da propriedade ou na concessão do uso da tecnologia, vez que para se garantir o recebimento dos proventos decorrentes da transferência das tecnologias que são desenvolvidas pelo individuo ou pelo setor privado, é necessária a formalização dos termos e condições desta transferência por meio da celebração de contratos.

Desta feita, as técnicas e as tecnologias desenvolvidas somente poderão ter uma indistinta aplicação se dispuserem de alicerces estruturais ou infraestrutura econômica e jurídica capaz de lhes conferir proteção e subsídios para sua correta comercialização e incorporação desta aos meios de produção.

Nesta toada, é oportuno verificar como se confere a proteção dessas transferências de tecnologia por meio desses contratos privados, bem como entender qual o papel do Estado e da ordem internacional nessa relação jurídica. Insta investigar outrossim como ocorre o controle na formação e execução desses contratos e qual o arcabouço normativo no Brasil capaz de reger tais relações.

Sendo assim, os contratos de transferência de tecnologia serão examinados com o propósito de destacar suas principais modalidades e cláusulas, bem como identificar o que se entende por tecnologia e como ocorre essa transferência, partindo da assertiva de consistem em um importante instrumento jurídico no comércio nacional e internacional.

\section{AUDACIOSO PAPEL DO ESTADO NOS SETORES DE DESENVOLVIMENTO NACIONAL}

A atuação do Estado no domínio econômico mostrou sua importância e vitalidade para a manutenção do sistema capitalista, tendo em vista que este é baseado em momentos de prosperidade e crise. A teoria de intervenção mínima estatal caiu por terra já no século XIX, com a apresentação das teorias econômicas 
Personalidade Acadêmica Homenageada:

Raymundo Juliano Feitosa (Universidade Federal do Rio Grande do Norte - UFRN)

amplamente difundidas de grandes expoentes como John Maynard Keynes ${ }^{1}$ e Joan Robinson².

Com a análise de estudos existentes no setor do desenvolvimento estatal, deparamo-nos com as previsões constitucionais que disciplinam e determinam a existência de uma ordem econômica e social. É preciso compreender que estas previsões foram feitas com objetivo de serem cumpridas, e não com mero intuito de previsão e criação de texto constitucional, tornando-se um mero escrito.

A primeira constituição brasileira que instituiu uma ordem econômica foi promulgada em 1934. O mencionado texto constitucional previa em seu artigo 115 que "a ordem econômica deve ser organizada conforme os princípios da Justiça e as necessidades da vida nacional, de modo que possibilite a todos existência digna. Dentro desses limites, é garantida a liberdade econômica ${ }^{3 "}$. Foi também esse documento normativo responsável por institucionalizar o direito de monopólio estatal da União em âmbito de interesse estratégico do desenvolvimento nacional.

É preciso destacar esse específico momento da história Brasileira, visto que, sem sombra de dúvidas foi Getúlio Vargas e sua equipe de estrategistas econômicos, adeptos das teorias cepalinas, os precursores do desenvolvimento no Brasil.

Getúlio Vargas foi, indubitavelmente, o mais importante personagem da história brasileira do século XX. No período em que foi figura central da política nacional, de 1930 a 1954, o país passou por transformações de vulto, alterando-se o papel do Estado e aprofundando sua inserção na economia e na sociedade ${ }^{4}$.

Foi justamente por essa postura arrojada que o termo "desenvolvimentismo", no cenário brasileiro, usualmente nos remete às teorias cepalinas, historicamente associado no Brasil com os governos de Getúlio Vargas e Juscelino Kubitschek, desempenhados a partir da década de 1950.

\footnotetext{
${ }^{1}$ Cf. KEYNES, John Maynard. As conseqüências econômicas da paz. São Paulo: Imprensa Oficial do Estado, 2002.

${ }^{2}$ Cf. Robinson, Joan. The Economics of Imperfect Competition. Londres: Macmillan, 1933.

${ }^{3}$ BRASIL. Constituição dos Estados Unidos do Brasil. Rio de Janeiro: Congresso Nacional, 1934.

${ }^{4}$ FONSECA, Pedro Cezar Dutra. Do progresso ao desenvolvimento: Vargas na Primeira República. In: BASTOS, Pedro Paulo Zahluth; FONSECA, Pedro Cezar Dutra (Orgs). A Era Vargas: desenvolvimentismo, economia e sociedade. São Paulo: Editora Unesp, 2012, p. 51.
} 
Personalidade Acadêmica Homenageada:

Raymundo Juliano Feitosa (Universidade Federal do Rio Grande do Norte - UFRN)

Na falta de uma definição mais precisa, o desenvolvimentismo é muitas vezes confundido com outros fenômenos associados a ele em experiências históricas mais típicas: defesa da industrialização e do intervencionismo, que vai desde políticas econômicas expansionistas, pró-crescimento, até o planejamento e a criação de empresas e bancos de fomento estatais, geralmente emoldurados por uma retórica com apelos ideológicos nacionalistas ${ }^{5}$.

Foi essa compreensão da necessidade de adotar políticas desenvolvimentistas, no sentido de tentar transformar a economia brasileira então baseada exclusivamente no setor agrário, que o Estado se propôs a adotar políticas públicas de cunho atuante também no setor econômico. Desde então, políticas econômicas são idealizadas e viabilizadas no sistema político brasileiro, o que importa em afirmar que o Estado quando se dedica a agir no sentido de melhorar as práticas mercadológicas efetuadas no Brasil, o faz com legitimidade para tanto.

A política econômica é assim mais detalhista e mais pragmática. Ela não discute as bases filosóficas do sistema. Procura, apenas, dentro de suas premissas, viabilizar os objetivos tidos como necessários ou desejáveis pela comunidade, servindo-se dos instrumentos que o próprio sistema coloca ao seu dispor. Ganha em exatidão e profundidade; perde em generalidade ${ }^{6}$.

A finalidade de instituir políticas de cunho econômico perpassa pela necessidade de colimar objetivos institucionais destinados à melhoria do setor. Genericamente, Fabio Nusdeo aponta que os fins, de caráter geral, consistem no progresso econômico, na estabilidade econômica, na justiça econômica e na liberdade econômica ${ }^{7}$.

Para o desenvolvimento específico da infraestrutura, diversas políticas públicas podem ser adotadas nos setores, por exemplo, de transportes,

\footnotetext{
${ }^{5}$ FONSECA, Pedro Cezar Dutra. Gênese e precursores do desenvolvimentismo no Brasil. In: BASTOS, Pedro Paulo Zahluth; FONSECA, Pedro Cezar Dutra (Orgs). A Era Vargas: desenvolvimentismo, economia e sociedade. São Paulo: Editora Unesp, 2012, p. 21.

${ }^{6}$ NUSDEO, Fábio. Curso de Economia: introdução ao Direito Econômico. 4 ed. rev. e atual. São Paulo: Editora RT, 2005, p. 171.

${ }^{7}$ NUSDEO, Fábio. Curso de Economia: introdução ao Direito Econômico. 4 ed. rev. e atual. São Paulo: Editora RT, 2005, p. 174.
} 
Personalidade Acadêmica Homenageada:

Raymundo Juliano Feitosa (Universidade Federal do Rio Grande do Norte - UFRN)

telecomunicações, abastecimento, saneamento, meio ambiente, energia, ciência e tecnologia.

Não é exaustivo mencionar Washington Peluso Albino de Souza e André Ramos Tavares, citados por Gilberto Bercovici e José Francisco Siqueira ${ }^{8}$, quando esclarecem que foi a Constituição de 1988 que inovou em relação às constituições anteriores por reconhecer de maneira mais enfática a importância da ciência e tecnologia. Aliás, é justamente esse conhecimento que assegurará o acesso ao conhecimento das futuras gerações.

Observa-se que as atuações do Estado no domínio social e econômico, tratam-se de temas que apesar de aparentemente diversos e esparsos, em verdade, abordam temáticas que desembocam no necessário e sadio desenvolvimento do Estado.

Dada estas premissas é possível vislumbrar que o desenvolvimento do Estado é feito primordialmente com planejamento do investimento que deve ser efetuado pelos setores estratégicos de crescimento. Isso não acontece, ou pelo menos não deveria acontecer, aleatoriamente. $O$ desenvolvimento é estratégico e acontece com base no estudo do que se pretende investir.

Destaca-se a obra desenvolvida por Mariana Mazzucato, "O Estado Empreendedor" na qual a autora pretende desmistificar todos os debates e entroncamentos criados tanto pelo setor privado, quanto pelo próprio setor público nos investimentos em pesquisa e desenvolvimento.

Tal obra foi escrita com base em uma versão ampliada de um relatório que a autora elaborou para a DEMOS, um instituto de pesquisa do Reino Unido, cujo objetivo era o de convencer o governo britânico a mudar de estratégia, destacando que em verdade o Estado deve ser encarado como verdadeiro empreendedor, que assume

\footnotetext{
${ }^{8}$ SOUZA, Washington Peluso Albino de. Primeiras linhas de direito econômico. 3.ed. São Paulo: LTr, 1994, p. 381/384; TAVARES, André Ramos. Ciência e tecnologia na Constituição, Revista de Informação Legislativa, no 175, jul./set. 2007, p. 7/8, apud BERCOVICI, Gilberto; SIQUEIRA NETO, José Francisco; Direito e Inovação Tecnológica. In: SCALQUETTE, Ana Cláudia S. (coord.); SIQUEIRA NETO, José Francisco (coord.); PINTO, Felipe Chiarello de Souza (org.); BAGNOLI, Vicente (org.). 60 desafios do direito: economia, direito e desenvolvimento. São Paulo: Atlas, 2013, p. 24.

${ }^{9}$ MAZZUCATO, Mariana. O Estado empreendedor: desmascarando o mito do setor público vs. Setor privado $=$ The Entrepreneurial State: Debunking Public vs. Private Sector Myths; tradução Elvira Serapicos. 1.ed. São Paulo: Portfolio-Penguin, 2014, p. 91/108.
} 


\section{Personalidade Acadêmica Homenageada:}

Raymundo Juliano Feitosa (Universidade Federal do Rio Grande do Norte - UFRN)

riscos e cria mercados. Assim não deveria cortar os programas do Estado em nome de uma economia "mais competitiva" e mais "empreendedora", mas repensar que o Estado pode e deve agir para assegurar uma recuperação sustentável pós-crise ${ }^{10}$.

A autora apresenta um excerto retirado do "The Washington Post", o qual relatava que o Presidente da França estava a passeio pelo Vale do Silício. Segundo consta, naquela oportunidade Thomas Perkins, investidor do capital de risco, exaltou as virtudes dos investidores arrojados que financiam os empreendedores, até que Paul Berg, ganhador do prêmio Nobel interrompeu sua fala questionando onde esses investidores estavam nos anos 1950 e 1960 quando foi preciso fazer todo investimento em pesquisa básica.

É com essa crítica feita no capítulo intitulado "O Estado arrojado: da 'redução de risco' ao 'manda ver'!", que Mazzucato inicia o desenvolvimento de sua ideia, cujo objeto central do debate proposto por ela é desvendar o maior mito de todos: a alegação que o Estado exerce um papel limitado para a produção de empreendedorismo, inovação e crescimento.

A autora explica que o debate sobre o tipo de pesquisa que o setor público ou o setor privado deve conduzir, resume-se à discussão sobre duas características: horizonte de tempo necessário e o fato de que muitos investimentos em pesquisa contribuem para o bem público. São essas duas questões que justificam o investimento pelo setor público em pesquisa básica e geram o argumento clássico da falha de mercado.

É preciso destacar que ao contrário do que transparece, o financiamento público de pesquisa básica, faz muito mais do que corrigir as falhas de mercado. Esse investimento público, em verdade, é muito mais disposto a se engajar no mundo da incerteza, e aí o setor público pode acabar criando produtos novos e mercados novos correspondentes a esses produtos.

Ao adentrar no mundo da incerteza econômica, o Estado lidera o processo de crescimento, ao contrário da ideia de que ele só incentiva ou estabiliza esse processo de crescimento. Esse ato de liderar é descrito como mero redutor de riscos, todavia

${ }^{10}$ MAZZUCATO, Mariana, op. cit. p. 24. 


\section{Personalidade Acadêmica Homenageada:}

Raymundo Juliano Feitosa (Universidade Federal do Rio Grande do Norte - UFRN)

esse discurso não merece prosperar tendo em vista que esse papel implica em uma atitude muito mais arrojada por parte do Estado, porque ele assume o risco, não apenas o elimina, para que subsidiariamente, alguém fique com o retorno.

Mazzucato explica que para desvendar esse mito de encarar o Estado como mero redutor de riscos, há a necessidade de mapear os tipos de riscos que podem ser encontrados no cenário de fomento à pesquisa, assim a análise pode ser devidamente compreendida.

Para que haja a devida compreensão da temática aqui abordada, é preciso compreender o que é o empreendedorismo. Tal definição não possui entendimento único e para que seja possível compreender o contexto que é adotado, traz-se aqui breve explicação de economistas renomados.

Segundo Joseph Alois Schumpeter ${ }^{11}$, empreendedor é alguém, ou um grupo de pessoas, disposto e capaz de transformar uma nova ideia ou invenção em uma inovação bem sucedida. Não é só montar um novo negócio, mas sim montar esse novo negócio de forma a produzir um novo produto, um novo processo, ou um novo mercado para um produto ou processo que já existe.

Para o economista essa troca implica numa destruição criativa e ela é a responsável pelo dinamismo das indústrias e do crescimento econômico a longo prazo.

Frank Knight e Peter Drucker por sua vez, afirmam que o empreendedorismo está ligado ao risco. O comportamento do empreendedor é o de uma pessoa que se dispõe a arriscar sua carreira e segurança financeira em nome de uma ideia, dispondo do seu tempo e também do seu capital num empreendimento incerto.

Perceba que há diferença entre risco e incerteza. Inclusive Knight faz essa distinção nos seguintes termos:

O comportamento do empreendedor é o de uma pessoa disposta a arriscar a
sua carreira e segurança financeira em nome de uma ideia, dispondo de seu
tempo e também de seu capital em um empreendimento incerto. [...] A

${ }^{11}$ SCHUMPETER, Joseph Alois. Economic Theory and Entrepreneurial History. Change and the Entrepreneur: Postulates and the Patterns for Entrepreneurial History. Research Center in Entrepreneurial History, Harvard University. Cambridge, MA: Harvard University Press, 1949, apud MAZZUCATO, Mariana, op. cit. p. 92. 
Personalidade Acadêmica Homenageada:

Raymundo Juliano Feitosa (Universidade Federal do Rio Grande do Norte - UFRN)

diferença prática entre as duas categ orias, risco e incerteza, é que na primeira a distribuição do resultado em um grupo de ocorrências é conhecida [...]. Ao passo que no caso da incerteza isso não se aplica, e a razão é que geralmente é impossível formar um grupo de ocorrências, pois a situação em questão é em grande medida única ${ }^{12}$.

Após essa breve explicação, retorna-se à abordagem dando ênfase para a inovação tecnológica. Investimentos em Pesquisa e Desenvolvimento que contribuem para a mudança tecnológica implicam em muitos produtos fracassados e quando existe o sucesso, ele leva muitos anos para conseguir materializar-se.

Fica claro observar que a inovação tecnológica não é pautada na sorte, mas sim fruto do acaso, isso porque ela baseia-se em estratégias de longo prazo e investimentos direcionados. Os retornos desses investimentos são altamente incertos e por isso não podem ser compreendidos por meio da teoria econômica racional.

É em razão do alto risco atrelado às características aleatórias do processo de inovação, que as empresas, ou seja, o setor privado, que busca na maioria das vezes exclusivamente a maximização do lucro, investem menos em pesquisa básica.

Estas empresas, quando investem em pesquisa, investem em pesquisa aplicada, pois este tipo de pesquisa possibilita um retorno maior e mais imediato do que a básica. Isso é passível de ser concluído com a análise dos seguintes gráficos, baseados em dados oriundos do sistema Norte Americano.

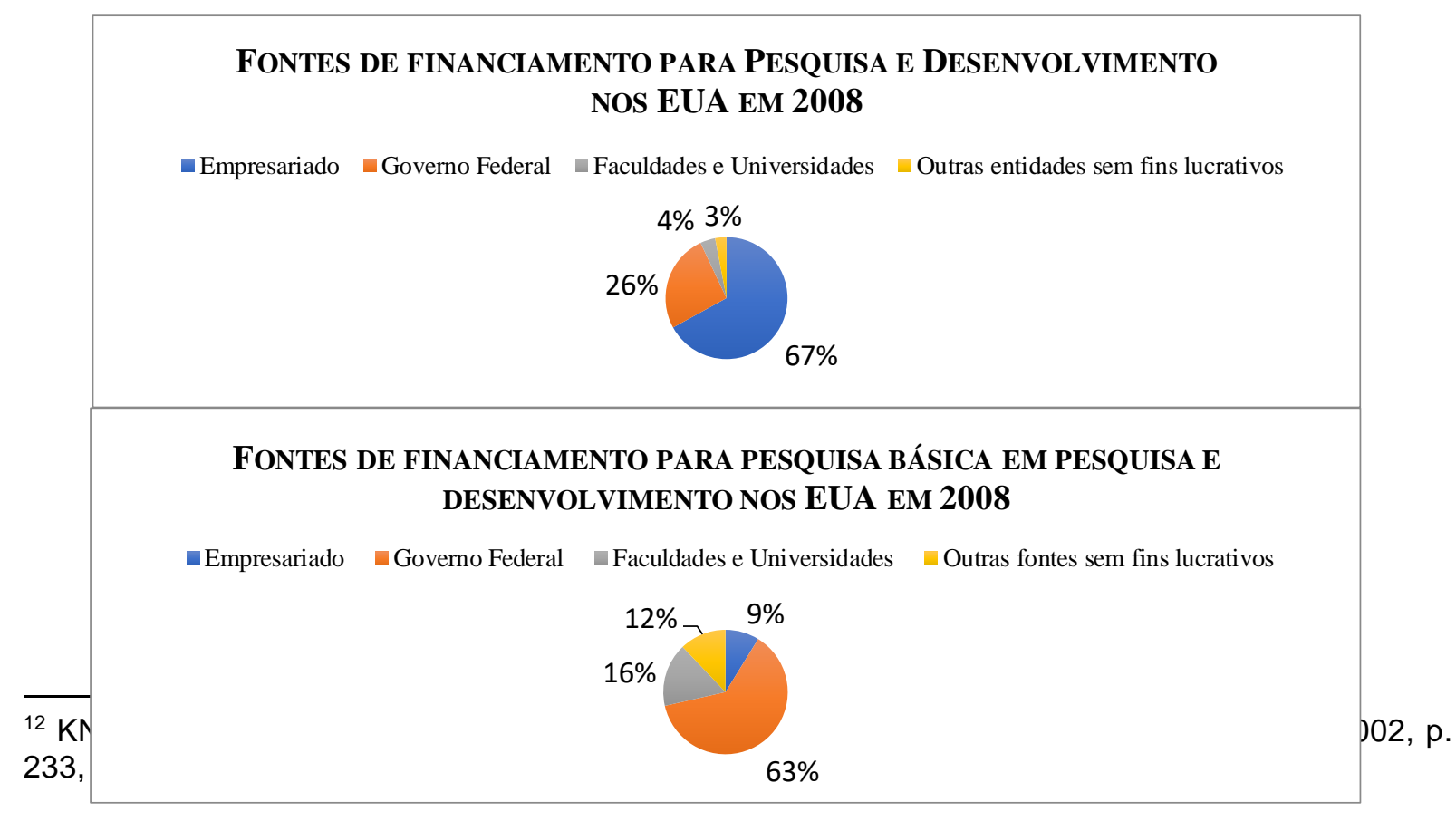


Personalidade Acadêmica Homenageada:

Raymundo Juliano Feitosa (Universidade Federal do Rio Grande do Norte - UFRN)

Fonte: National Science Foundation (2008).

É possível observar pela breve análise dos dados aqui colacionados que $67 \%$ dos gastos com pesquisa de maneira generalizada é oriunda do setor empresariado. Entretanto, com a análise da específica pesquisa básica, é possível constatar a liderança do setor Estatal nesse campo de atuação. Note que parte das Universidades e Faculdades se utilizam de verba pública, o que, grosso modo, aumentaria a participação do Estado em pesquisa básica. A clara conclusão é a de que o Estado é quem lidera a inovação radical, a verdadeira inovação, por tratar-se de algo arriscado.

É preciso destacar que a teoria da atuação do Estado apenas em razão de uma falha de mercado não é verdadeira. O governo não só financia a pesquisa mais arriscada, seja a básica ou a aplicada, como também muitas vezes foi a fonte da inovação mais radical e pioneira. Perceba que o governo se empenha na criação de mercados, ao invés de apenas corrigi-los.

Esclarece-se que não é toda inovação que gera um amplo desenvolvimento econômico. As inovações capazes de gerar esse amplo desenvolvimento econômico, necessariamente, são detentoras de três qualidades fundamentais: elas se infiltram, espalhando-se por vários setores; elas melhoram com o tempo, reduzindo os custos para os seus usuários; elas facilitam a geração de inovação, através da invenção e da produção de novos produtos ou processos.

\section{OS CONTRATOS DE TRANSFERÊNCIA DE TECNOLOGIA: LIÇÕES PROPEDÊUTICAS ACERCA DA TEORIA GERAL DOS CONTRATOS SOB A ÓTICA DOS CONTRATOS DE TRANSFERÊNCIA DE TECNOLOGIA}

O ideário do desenvolvimento tecnológico como sendo um dos fatores determinantes para o desenvolvimento social e econômico das nações é comumente 


\section{Personalidade Acadêmica Homenageada:}

Raymundo Juliano Feitosa (Universidade Federal do Rio Grande do Norte - UFRN)

aceito pela vasta doutrina que estuda o desenvolvimento da humanidade. Esse progresso constante, centralizando na ação humana como força motriz, é visto pelo professor João Assafim ${ }^{13}$ como uma linha de avanços constantes e em ritmo acelerado e que tem suas raízes no que chama de patrimônio dos conhecimentos tecnológicos.

$\mathrm{Na}$ contemporaneidade, $\mathrm{O}$ ato de inventar é o principal alicerce para o crescimento econômico e desenvolvimento dos países. A hegemonia econômica das nações desenvolvidas em comparação com as nações em que se encontram em vias de desenvolvimento ocorre justamente pelo incentivo e investimentos coordenados entre poder público e privado visando o desenvolvimento de novas tecnologias.

Inegável, portanto, que há uma preocupação não somente particular como também estatal para $\circ$ avanço e aprimoramento da tecnologia, visando, primordialmente, a solução de problemas brasileiros e o desenvolvimento do sistema produtivo nacional e é frente a esse incontestável fato desenvolvimentista que a ciência deve se posicionar de forma a possibilitar sua tutela perante os cidadãos. $O$ instituto jurídico denominado contrato de transferência de tecnologia vai ao encontro desse propósito, renovando o método de aplicação do direito e proporcionando a devida segurança aos sujeitos envolvidos.

O contrato de transferência de tecnologia abrange diferentes objetos que possuem características jurídicas próprias, porém, independentemente do objeto, todos os contratos devem pautar-se em regras básicas denominadas na doutrina como "Teoria Geral dos Contratos". A necessidade de abalizar tais conceitos propedêuticos não é mera formalidade acadêmica, uma vez que, considerando a ausência de legislação específica para essa modalidade contratual, é preciso destacar uma série de aspectos inerentes à essa modalidade para que possa construir sua teoria geral e facilitar a sua compreensão.

A definição de contratos pode ser traduzida como a manifestação de duas ou mais vontades, visando a criação, regulamentação, alteração ou extinção de uma

\footnotetext{
${ }^{13}$ ASSAFIM, João Marcelo de Lima. A transferência de Tecnologia no Brasil, 2.ed., Rio de Janeiro: Editora Lumen Juris, 2010, p. 3
} 
Personalidade Acadêmica Homenageada:

Raymundo Juliano Feitosa (Universidade Federal do Rio Grande do Norte - UFRN)

relação jurídica de caráter patrimonial ${ }^{14}$. O contrato constitui-se numa declaração de vontade destinada a produzir efeitos jurídicos ${ }^{15}$.

O contrato vai constituir uma forma de negócio jurídico de natureza bilateral (duas partes) ou plurilateral (mais de duas partes) que depende de um acordo de vontades para sua celebração como ato regulamentador de interesses privados ${ }^{16}$.

Não há dúvidas que tais definições se aplicam perfeitamente ao presente estudo, pois, o contrato de transferência de tecnologia é um acordo em que há a expressão de vontades entre seus signatários, capaz de produzir efeitos jurídicos envolvendo seus interesses privados de caráter patrimonial. Tais contratos traduzem acordos verbais ou expressos envolvendo o desenvolvimento de inovações tecnológicas, a exploração temporária dos direitos da propriedade industrial, bem como o conhecimento técnico para terceiros ${ }^{17}$.

O objetivo ou a finalidade deste contrato é visar a capacitação tecnológica e/ou aperfeiçoamento técnico de um processo produtivo ou de um produto final mediante a introdução de técnica nova na produção possibilitada pela transmissão contratual da tecnologia ${ }^{18}$.

Por fim, o Código Civil Brasileiro vai disciplinar em seu artigo 421 que: "A liberdade de contratar será exercida em razão e nos limites da função social do contrato ${ }^{19 "}$. A autonomia da vontade se alicerça na ampla liberdade contratual, tendo a faculdade ou não de celebrar contratos mediante acordo de vontades, suscitando efeitos tutelados pela ordem jurídica, sem qualquer interferência do Estado ${ }^{20}$. Importante destacar que essa autonomia de vontade entre as partes não tem caráter absoluto, uma vez que o Estado está apto a interferir nessas relações contratuais

\footnotetext{
${ }^{14}$ AZEVEDO, Álvaro Villaça. Teoria geral dos contratos típicos e atípicos, 3. ed., São Paulo: Atlas, 2009 , p. 9.

${ }^{15}$ VENOSA, Sílvio de Salvo. Direito civil: teoria geral das obrigações e teoria geral dos contratos, V. 2. 14. ed., São Paulo: Atlas, 2014, p. 395.

${ }^{16}$ DINIZ, Maria Helena. Direito Civil Brasileiro, v. 3. São Paulo: Saraiva, 2002, p. 23.

${ }^{17} \mathrm{BLASI}$, Gabriel Di. A Propriedade Industrial, 3.ed., Rio de Janeiro: Editora Forense, 2010, p. 360

${ }^{18}$ ASSAFIM, João Marcelo de Lima. A transferência de Tecnologia no Brasil, 2.ed., Rio de Janeiro: Editora Lumen Juris, 2010, p. 106.

${ }^{19}$ BRASIL. Código civil - Lei no 10.406, de 10 de janeiro de 2002.

${ }^{20}$ GONÇALVES, Carlos Roberto. Direito Civil brasileiro 3 - Contratos e atos unilaterais, 13. Ed., São Paulo: Saraiva, 2015, p. 41
} 
Personalidade Acadêmica Homenageada:

Raymundo Juliano Feitosa (Universidade Federal do Rio Grande do Norte - UFRN)

quando, de alguma forma, for necessário impor obrigações e limitações de ordem econômica.

A probidade e a boa-fé estão comtempladas no artigo 422 do Código Civil ${ }^{21}$ da seguinte forma: "Os contratantes são obrigados a guardar, assim na conclusão do contrato, como em sua execução, os princípios de probidade e boa-fé" compreendem o âmago do próprio entendimento entre os seres humanos. Pertencem ao estado de espírito que leva o sujeito a praticar um negócio jurídico em clima de aparente segurança22.

A observância dessas lições básicas a respeito da teoria geral dos contratos, faz com os contratos de transferência de tecnologia se tornem legítimos e aptos, sob o aspecto formal, a requerem a devida averbação perante o Instituto Nacional da Propriedade Industrial - INPI - e efetividade perante terceiros.

\section{A CONFIGURAÇÃO CONCEITUAL DE TECNOLOGIA E OS ASPECTOS INERENTES AOS CONTRATOS DE TRANSFERÊNCIA DE TECNOLOGIA}

Muito embora quase todo mundo consiga vislumbrar a definição de tecnologia, ainda que de forma abstrata, para fins acadêmicos há necessidade de colacionar conceitos propedêuticos para que o estudo dessa temática seja feito com precisão. Será possível perceber que não há uma definição exata e uníssona deste conceito multidimensional, todavia, o que se propõe a seguir, é relacionar alguns entendimentos doutrinários que possibilitam uma visão panorâmica deste assunto.

Akira Chinen ensina que a tecnologia é toda a experiência vivida por uma pessoa desde a criação, seja através de dados técnicos ou empíricos, até sua total incorporação, visando a obtenção de finalidades conjecturadas ${ }^{23}$. Arremata Chinen afirmando que a tecnologia "é mercadoria diferente das demais em sua forma, por ser

\footnotetext{
${ }^{21}$ BRASIL. Código civil - Lei no 10.406, de 10 de janeiro de 2002.

${ }^{22}$ AZEVEDO, Álvaro Villaça. Teoria geral dos contratos típicos e atípicos, 3. ed., São Paulo: Atlas, 2009 , p. 15.

${ }^{23}$ CHINEN, Akira. Know-how e Propriedade Industrial, São Paulo: Editora Oliveira Mendes, 1997, p.5
} 
Personalidade Acadêmica Homenageada:

Raymundo Juliano Feitosa (Universidade Federal do Rio Grande do Norte - UFRN)

impalpável e não visível; é algo que existe só no domínio das ideias e sem base material" 24 .

Pode-se dizer também que a tecnologia é o bem incorpóreo envolvendo os conhecimentos técnicos e científicos os quais são passiveis de aplicação prática em uma determinada atividade industrial ou similar para a consequente obtenção de um bem corpóreo ${ }^{25}$.

Cesar Flores vai definir tecnologia sob dois aspectos, o conhecimento e a informação:

Considera-se tecnologia o conhecimento ou a informação que possa trazer alguma vantagem competitiva no campo comercial ou industrial, sendo conhecimento todo saber tecnológico, científico, literário ou artístico nos domínios teórico ou prático, enquanto informação é o conjunto de esclarecimentos acerca de procedimento para utilização do conhecimento ${ }^{26}$

Percebe-se que, enquanto que no plano imaterial o elemento de maior destaque é o conhecimento, no plano material e no âmbito da transferência de tecnologia, esse conhecimento só se torna útil na medida em que confere alguma vantagem comercial e, sendo assim, para que esse saber de alguma forma seja transmitido, há a necessidade de construção de instrumento jurídico capaz de conferir proteção. Em sentido amplo, "a transferência de tecnologia significa um negócio jurídico pelo qual uma das partes se obriga a transmitir determinados conhecimentos aplicáveis a um processo produtivo, sendo remunerado pela outra parte"27.

A Organização Mundial da Propriedade Intelectual (World Intellectual Property Organization - WIPO) define transferência de tecnologia como uma série de processos de compartilhamento ou aquisição de ideias, conhecimentos, tecnologia, técnicas e

\footnotetext{
${ }^{24}$ Idem

${ }^{25} \mathrm{BLASI}$, Gabriel Di. A Propriedade Industrial, 3.ed., Rio de Janeiro: Editora Forense, 2010, p. 28

${ }^{26}$ FLORES, Cesar. Segredo industrial e o know-how: aspectos jurídicos internacionais. Rio de Janeiro: Editora Lumen Juris, 2008, p. 6.

${ }_{27}$ CORREA, Daniel Rocha. Contratos de transferência de tecnologia: controle de práticas abusivas e cláusulas restritivas. Belo Horizonte: Movimento Editorial da Faculdade de Direito da UFMG, 2005, p. 96;
} 
Personalidade Acadêmica Homenageada:

Raymundo Juliano Feitosa (Universidade Federal do Rio Grande do Norte - UFRN)

pesquisas científicas entre indivíduos ou instituições públicas e privadas ${ }^{28}$. A modalidade de transferência de tecnologia refere-se a tecnologia como todo conhecimento que pressuponha alguma aplicabilidade na ciência industrial, técnica ou de serviço que será repassada de forma definitiva ou temporária ${ }^{29}$.

Durante algum tempo, o INPI utilizou o temo "transferência de tecnologia" de forma genérica, abrangendo os institutos do licenciamento do uso de marcas e exploração de patentes; fornecimento de tecnologia e serviços de assistência técnica; e os contratos de franquia ${ }^{30}$. Com a edição da lei que criou a Contribuição de Intervenção no Domínio Econômico (CIDE) sobre royalties ${ }^{31}$ e Instrução Normativa n. 16/2013 emanada pelo INP|32 houve a confirmação expressa da abrangência do termo "transferência de tecnologia" a qual encampou definitivamente a exploração de patentes; fornecimento de tecnologia; prestação de serviços de assistência técnica e científica e franquia.

Independentemente do objeto do contrato de transferência de tecnologia, temse em mente que a exploração dessa tecnologia vai proporcionar o atingimento de dois objetivos principais, a maximização da remuneração da tecnologia mediante a otimização da sua exploração e a utilização da tecnologia como forma de ingresso em novos mercados ${ }^{33}$. Essa circulação de tecnologia vai se materializar através dos contratos de transferência que não necessariamente significam transferir a titularidade da propriedade e sim o repasse do conhecimento.

\footnotetext{
${ }^{28}$ World Intellectual Property Organization. Standing Committee on the Law of Patents, Transfer of Technology, Genebra, 2010, disponível em: http://www.wipo.int/edocs/mdocs/scp/en/scp_17/scp_14_4_rev_2.pdf, acesso em 20.06.2017, tradução livre.

${ }^{29}$ FLORES, Cesar, op. cit. p. 24.

${ }^{30}$ Ato Normativo n.135, de 15.04.1997, artigo 20 "O INPI averbará ou registrará, conforme o caso, os contratos que impliquem transferência de tecnologia, assim entendidos os de licença de direitos (exploração de patentes ou de uso de marcas) e os de aquisição de conhecimentos tecnológicos (fornecimento de tecnologia e prestação de serviços de assistência técnica e científica) e os contratos de franquia."

${ }^{31}$ Lei n. 10.168 de 29.12.2000, alterada pela Lei n. 10.332 de 19.12.2001, artigo $2^{\circ}$ $\S 1^{\circ}$ "Consideramse, para fins desta Lei, contratos de transferência de tecnologia os relativos à exploração de patentes ou de uso de marcas e os de fornecimento de tecnologia e prestação de assistência técnica. "

32 BRASIL. Instrução Normativa n. 16/2013 emanada pelo Ministério Do Desenvolvimento, Indústria e Comércio Exterior Instituto Nacional da Propriedade Industrial Disponível em: <http://www.inpi.gov.br/legislacao-1/instrucao_normativa_16-2013.pdf>. Acesso em:.11 de jul. 2017.

${ }^{33}$ PRADO, Maurício Curvelo de Almeira. Contrato Internacional de Transferência de Tecnologia patente e know-how, Porto Alegre: Livraria do Advogado, 1997, p. 17
} 
Personalidade Acadêmica Homenageada:

Raymundo Juliano Feitosa (Universidade Federal do Rio Grande do Norte - UFRN)

Dessa forma, esse tipo de contrato deve fornecer os dados técnicos de engenharia, processo ou do produto, incluindo a metodologia do desenvolvimento tecnológico daquela tecnologia que está sendo transferida ${ }^{34}$. O contrato ainda deve detalhar o conjunto de dados e informações técnicas inerente àquela tecnologia, bem como estipular as formas e os prazos de pagamento; a remuneração ou os royalties; a responsabilidade pelo pagamento do Imposto de Renda e o prazo de exploração daquela tecnologia, conforme fixado pelo INPI através do Ato Normativo 135/9735.

Outra questão de relevância neste âmbito diz respeito a internacionalidade desses contratos. Isso porque, com a crescente globalização, as tecnologias tendem a extrapolar as fronteiras dos países e circularem pelo mundo o que possibilita, inclusive, o ingresso em novos mercados. Assim, os contratos que regem essa transferência internacional terão que ser protegidos e regulamentados pelo Direito Internacional Privado, além de se adequarem às exigências dos sistemas jurídicos locais, tratados internacionais correlatos e interferência do poder público brasileiro.

Nesta toada, o poder público tem capacidade de interferir nas relações negociais privadas, muito embora as partes tenham liberdade para contratar, por força de questões políticas, econômicas ou de proteção da sociedade, sob a premissa de que os conhecimentos devem ser transferidos em consonância com as relações internacionais estabelecidas com os demais países de forma a assegurar a defesa nacional ${ }^{36}$.

34 RODRIGUES JUNIOR, Edson Beas et al (Org.). Propriedade Intelectual: Novos paradigmas internacionais, conflitos e desafios. Rio de Janeiro: Elsevier, 2007, p. 560

${ }^{35}$ Ato Normativo no 135 de 15 de abril de 1997 - "1. Resolve: Normalizar os procedimentos de averbação ou registro de contratos de transferência de tecnologia e de franquia, na forma da LPI e de legislação complementar"

${ }^{36}$ PRADO, Maurício Curvelo de Almeira. Contrato Internacional de Transferência de Tecnologia patente e know-how. Porto Alegre: Livraria do Advogado, 1997, p. 61 
Personalidade Acadêmica Homenageada:

Raymundo Juliano Feitosa (Universidade Federal do Rio Grande do Norte - UFRN)

\section{A CARACTERIZAÇÃO DO KNOW-HOW E AS FORMAS DE TRANSFERÊNCIA DESSA TECNOLOGIA}

Superadas as lições acerca do conceito de tecnologia e sua transferência através de um contrato, passa-se ao estudo do contrato de know-how que advém da expressão americana "know-how to do it "que quer dizer: saber como fazer isso ${ }^{37}$.

É importante, antes de adentrar a este assunto específico, esclarecer que ainda há muita discussão envolvendo a semântica da expressão know-how, principalmente quando ela está atrelada a um contrato de licença ou cessão de knowhow. Outro ponto controvertido na doutrina é a utilização de know-how como sinônimo de segredo industrial. Independentemente, para fins de estudo dessa temática, não serão trazidos ao debate aspectos controversos e polêmicos dessas questões.

A tecnologia é algo que existe no âmbito das ideias de seu possuidor, faz parte de seu conhecimento intrínseco, porém de forma abstrata. Quando esse conhecimento se materializa através de um passo a passo metodológico ele se torna uma invenção, ou seja, a criação de algo novo em forma de objeto. Esse passo a passo metodológico é chamado de know-how.

Em outras palavras, o know-how é o modo prático de fabricação de um determinado produto ou a reprodução de um determinado conhecimento, aplicável a um processo produtivo, que não é de domínio público. Cesar Flores traz quatro elementos que definem o know-how quando objeto de um contrato são eles: i) o conjunto de conhecimentos técnicos; ii) secretos, ou seja, não disponíveis ao público, iii) intangível pela sua própria natureza imaterial, iv) com valor econômico dentro de um contexto empresarial ${ }^{38}$. Ou seja, esse conhecimento quando aplicado possibilita um real incremento da atividade produtiva, seja na qualidade do produto, aumento da produção, redução do tempo de fabricação, dentre inúmeras outras possibilidades.

\footnotetext{
${ }^{37}$ CHINEN, Akira. Know-how e Propriedade Industrial, São Paulo: Editora Oliveira Mendes, 1997, p. 5

${ }^{38}$ FLORES, Cesar, op. cit. p. 35.
} 
Personalidade Acadêmica Homenageada:

Raymundo Juliano Feitosa (Universidade Federal do Rio Grande do Norte - UFRN)

Há de se frisar que quando o know-how é objeto de contrato ele deve ser indisponível ao público (secreto), ou seja, uma tecnologia não patenteada ${ }^{39}$ ou não sujeita ao direito de propriedade e com aplicabilidade industrial.

Neste ponto específico pode surgir o questionamento do porquê o indivíduo detentor daquele know-how prefere ceder ou transferir ao invés de depositar o pedido de patente daquela tecnologia. Neste caso há quatro justificativas que podem esclarecer de forma muito precisa os motivos que envolvem essa escolha, dentre elas estão a perda da patente para o domínio público, a diluição da tecnologia no mercado e os custos envolvidos no pedido de patente, veja-se:

Um, porque o sistema de patentes é estruturado com base na publicidade. A
patente é um direito concedido pelo governo, mas exige como contrapartida
que a invenção se torne pública [...] para que, vencido o seu período de
proteção, terceiros possam colocar no mercado produtos que incorporem
aquela invenção. Dois, porque é proteção por período de tempo determinado.
A três, porque para fazer valer estes direitos é preciso acionar o judiciário, o
que implica custos, determinado prazo e alguma incerteza jurídica quanto ao
deslinde da questão. E a quatro, como o processo de patenteamento de uma
invenção implica custos, é um procedimento efetuado antes mesmo de se ter
a exata noção do sucesso comercial da invenção; [...] Vale notar que, quando
se patenteia uma determinada invenção em um país [...] Os bancos de
patentes são abertos para acesso internacional, o que implica que outras
empresas, [...] possam utilizá-la livremente, sem ter violado um segredo
comercial, já que a publicidade conferida à invenção foi autorizada pelo
próprio titular ao submeter-se ao processo de obtenção do direito de patente 40

Outra questão importante é que muitas vezes a tecnologia que foi desenvolvida ainda não é passível de registro ${ }^{41}$ por estar em fase experimental e, portanto, não podo ser classificada como invenção. Por esta razão, o possuidor da tecnologia, invariavelmente, terá que optar pelos institutos do direto contratual se tiver interesse em promover a circulação desse conhecimento técnico.

\footnotetext{
${ }^{39}$ Neste aspecto quando se fala em tecnologia não patenteada significa dizer que aquele conhecimento não se tornou objeto de uma patente, mas não significa que ele não tem proteção jurídica.

40 FRANCO, Karin Klempp. A regulação da contratação internacional de transferência de tecnologia - perspectiva do direito de propriedade industrial, das normas cambiais e tributárias e do direito concorrencial. 2010. 242 f. Tese (Doutorado) - Curso de Direito, Direito Comercial, Faculdade de Direito da Universidade de São Paulo, São Paulo, 2010. Disponível em: $<$ www.teses.usp.br/teses/disponiveis/2/2132/tde.../Microsoft_Word_VersaoParcial.pdf>. Acesso em: 10 jul. 2017.

${ }^{41}$ De acordo com o artigo 8 da Lei oㅜ 9.279, de 14 de maio de 1996 é patenteável a invenção que atenda aos requisitos de novidade, atividade inventiva e aplicação industrial.
} 
Personalidade Acadêmica Homenageada:

Raymundo Juliano Feitosa (Universidade Federal do Rio Grande do Norte - UFRN)

Em suma, essa modalidade contratual atípica, é bilateral, ou seja, prevê a existência de duas partes física ou jurídica em que há a obrigação onerosa de transmissão de conhecimentos no que se refere a um processo especial de fabricação, de fórmulas secretas, de técnicas ou de práticas originais, durante certo tempo ${ }^{42}$. Tais conhecimentos e demais obrigações negociais devem estar expressamente contidas de forma certa e determinada razão pela qual este contrato é considerado comutativo. Ademais o referido contrato é sinalagmático em razão de conter obrigações mútuas aos envolvidos no sentido de enquanto detentor da tecnologia se obriga a fornecer todos os detalhes da aplicabilidade daquele conhecimento o receptor se obrigada ao pagamento e também a confidencialidade da utilização.

Importante salientar que nada impede que os contratos de transferência de know-how sejam feitos de forma gratuita ao invés de onerosa. As partes são livres para contratar da forma que melhor lhes couber, porém tal contratação não é usual tendo em vista a importância da tecnologia que é transferida e seu alto grau de valoração econômica ${ }^{43}$.

Essa transmissão de know-how pode ocorrer de três formas básicas, a prestação de serviços de assistência técnica, a licença ou a cessão. No que se refere a assistência técnica, a concessão do know-how ocorre de forma indireta, uma vez que a transferência da tecnologia não é tida com o objeto principal do contrato e sim o serviço que será prestado que, por sua vez, reúne todo o conhecimento técnico necessário. Por outro lado, optando pela licença de know-how, o detentor ${ }^{44}$ concede autorização ao licenciado para utilização das informações por tempo determinado sem que haja a transferência da titularidade do know-how. De outra borda, optando pela

\footnotetext{
42 CARVALHO, Carlos Eduardo Neves de. Contratos de know-how (fornecimento de tecnologia), In Revista da ABPI, n. 128, jan/fev 2014, p. 33

${ }^{43}$ Santos, Nivaldo dos. Instrumentos contratuais de gestão da propriedade intelectual, Goiânia: Ed. De UCG, 2007, p.25

${ }^{44}$ Neste aspecto específico vale traçar o seguinte comentário: No entendimento de Elizabeth Fekete não se pode afirmar que o detentor do know-how seja considerado titular, pois não se trata de propriedade, mas tão somente de uma posse de um conhecimento aplicável in FEKETE, Elizabeth Kasznar. O regime jurídico do segredo de indústria e comércio no direito brasileiro, Rio de Janeiro: Forense, 2003, p. 169. Dessa forma, para não gerar discussões doutrinária a respeito do assunto, utilizou-se detentor e não titular em conformidade com a lição de Fekete.
} 
Personalidade Acadêmica Homenageada:

Raymundo Juliano Feitosa (Universidade Federal do Rio Grande do Norte - UFRN)

utilização da cessão, o titular transfere a titularidade ao adquirente daquele conhecimento específico ${ }^{45}$.

Tais contratos estão sujeitos a requisitos mínimos para estarem aptos a averbação perante o INPI, são eles: i) objeto do contrato ser uma tecnologia não patenteada; ii) delimitação do prazo contratual; iii) remuneração e iv) responsabilidade pelo pagamento do Imposto de Renda ${ }^{46}$. Neste caso também há a limitação temporal de 5 (cinco) anos para a duração do contrato, sendo este prazo passível de prorrogação por mais 5 (cinco) anos.

Neste liame de ideia é que se passa ao estudo do tópico seguinte no tocante a competência do INPI na regulamentação dos contratos de transferência de tecnologia e a necessidade de sua averbação perante o órgão.

\section{O INPI NO PROCESSO DE AVERBAÇÃO DOS CONTRATOS DE TRANSFERÊNCIA DE TECNOLOGIA}

A discussão acerca da autonomia privada frente a interferência do poder público no âmbito dos contratos de tecnologia não é contemporânea, muito já se discutiu sobre essa temática e muitas questões, inclusive, já foram superadas, todavia, faz-se necessário traçar alguns comentários de modo a aclarar a função do INPI, bem como o papel do poder público em contrapartida aos limites da liberdade de contratar.

No Brasil todas as questões relativas à Propriedade Industrial devem ser submetidas ao INPI, conforme explicado em seu sítio eletrônico ${ }^{47}$. A lei $n^{\circ}$ 5.648, de

\footnotetext{
${ }^{45}$ FLORES, Cesar, op. cit. p.89

${ }^{46}$ CARVALHO, Carlos Eduardo Neves de. op. cit. p. 40

47“Criado em 1970, o INPI é uma autarquia federal vinculada ao Ministério da Indústria, Comércio Exterior e Serviços, responsável pelo aperfeiçoamento, disseminação e gestão do sistema brasileiro de concessão e garantia de direitos de propriedade intelectual para a indústria. Entre os serviços do INPI, estão os registros de marcas, desenhos industriais, indicações geográficas, programas de computador e topografias de circuitos, as concessões de patentes e as averbações de contratos de franquia e das distintas modalidades de transferência de tecnologia. $\mathrm{Na}$ economia do conhecimento, estes direitos se transformam em diferenciais competitivos, estimulando o surgimento constante de novas identidades e soluções técnicas. " Disponível em http://www.inpi.gov.br/sobre/estrutura, acesso em 30.07.2017
} 
Personalidade Acadêmica Homenageada:

Raymundo Juliano Feitosa (Universidade Federal do Rio Grande do Norte - UFRN)

11 de dezembro de 1970 que promoveu a criação do Instituto Nacional da Propriedade Industrial dispõe em seu artigo $2^{\circ}$ que o INPI tem por finalidade principal executar, no âmbito nacional, as normas que regulam a propriedade industrial, tendo em vista a sua função social, econômica, jurídica e técnica. ${ }^{48}$ Por sua vez, o artigo 211 da Lei no 9.279 , de 14 de maio de $1996^{49}$ que regulamenta os direitos e obrigações relativos à propriedade industrial determina que o INPI fará o registro dos contratos que impliquem na transferência de tecnologia para produzirem efeitos em relação a terceiros ${ }^{50}$.

$\mathrm{Na}$ lição de Gabriel Di Blasi51, a averbação dos contratos no INPI é indispensável para três principais propósitos: i) produção de efeitos perante terceiros; ii) efetivação de remessas ao exterior como contraprestação à outorga de direitos ao licenciado local e iii) admissão de dedução fiscal dos royalties e remunerações decorrentes dos contratos de transferência de tecnologia como despesas operacionais.

A Instrução Normativa o 70 de 11 de abril $2017^{52}$ emanada pelo INPI dispõe sobre o procedimento administrativo de registro de contratos de transferência de tecnologia determina em seu artigo $5^{\circ}$ que, além da apresentação do contrato de transferência de tecnologia, os pedidos de averbação devem conter expressamente as partes contratantes; modalidade contratual; objeto do contrato; valor do contrato; moeda, forma de pagamento; prazo de vigência do contrato e outras especificações que se fizerem necessárias e forem relacionadas ao contrato. Após a análise desses elementos, o INPI poderá deferir, formular exigência, indeferir ou arquivar o pedido.

\footnotetext{
48 BRASIL. Lei $\mathrm{n}^{\circ} 5.648$, de 11 de dezembro de 1970 . Disponível em: <http://www.planalto.gov.br/ccivil_03/Leis/L5648.htm>. Acesso em 30. jun. 2017

49 BRASIL. Lei no 5.648, de 11 de dezembro de 1970. Disponível em: <http://www.planalto.gov.br/ccivil_03/leis/L9279.htm>. Acesso em 30.jun.2017

${ }^{50}$ Há também algumas legislações complementares que versam conjuntamente sobre a necessidade de averbação prévia dos contratos de transferência de tecnologia perante o INPI para que seja possível a dedução fiscal das importâncias pagas no Imposto de Renda, efetivação da remessa de valores ao exterior, dentre outras questões, são elas a lei no 3.470 , de 28 de novembro de 1958; Lei no 4.506, de 30 de novembro de 1964 e lei no 8.883, de 8 de junho de 1994.

${ }^{51}$ BLASI, Gabriel Di. A Propriedade Industrial, 3.ed., Rio de Janeiro: Editora Forense, 2010, p. 369.

52 BRASIL. Instrução Normativa INPI/PR № 070, de 11 de abril de 2017 Disponível em http://www.inpi.gov.br/menu-servicos/transferencia/arquivos/legislacao-transferencia-de-

tecnologia/IN702017Procedimentoadministrativodeaverbaodelicenasecesses.pdf., acesso em 03.07.2017
} 
Personalidade Acadêmica Homenageada:

Raymundo Juliano Feitosa (Universidade Federal do Rio Grande do Norte - UFRN)

Explica Cesar Flores ${ }^{53}$ que as decisões do INPI têm seguido um rol analítico para que se entenda haver transferência, são eles: i) a não existência de tecnologia disponível no pais; ii) importe no aumento da capacidade de produção da receptora; iii) haja responsabilidade da supridora pela tecnologia; iv) haja absorção ou autonomia e v) que o vem transmitido seja de natureza imaterial.

Com base nisso, destaca-se o papel do INPI como regulador desta modalidade contratual privada, visto que, não obstante o cumprimento das regras estabelecidas pelo artigo 104 do Código Civil no tocante aos requisitos de validade do contrato, o INPI poderá indeferir o pedido de averbação ou registro com base em questões administrativas internas e também questões econômicas, tendo em vista a sua função social, econômica, jurídica e técnica.

Nesta toada, a capacidade do poder público de interferir nas relações negociais privadas fica realçada pois, embora as partes tenham liberdade para contratar, fica estabelecido que os conhecimentos devem ser transferidos em consonância com as relações internacionais estabelecidas com os demais países de forma a assegurar a defesa nacional ${ }^{54}$.

Um exemplo dessa interferência na autonomia privada se dá por força do Acordo TRIPS - Agreement on Trade-Related Aspects of Intellectual Property Rights (Acordo sobre Aspectos dos Direitos de Propriedade Intelectual Relacionados ao Comércio) - em vigor no Brasil desde 1994. Em seu artigo $40^{55}$ há previsão expressa de cláusulas abusivas que visam a restrição da concorrência desleal e que não possuem como fonte de criação a função social do contrato, mas sim uma

\footnotetext{
${ }^{53}$ FLORES, Cesar, op. cit. p 230.

54 PRADO, Maurício Curvelo de Almeida. Contrato Internacional de Transferência de Tecnologia patente e know-how, Porto Alegre: Livraria do Advogado, 1997, p. 61

${ }^{55}$ BRASIL, decreto no 1.355, de 30 de dezembro de 1994 - Artigo 40: 1. Os Membros concordam que algumas práticas ou condições de licenciamento relativas a direitos de propriedade intelectual que restringem a concorrência podem afetar adversamente o comércio e impedir a transferência e disseminação de tecnologia. 2. Nenhuma disposição deste Acordo impedirá que os Membros especifiquem em suas legislações condições ou práticas de licenciamento que possam, em determinados casos, constituir um abuso dos direitos de propriedade intelectual que tenha efeitos adversos sobre a concorrência no mercado relevante. Conforme estabelecido acima, um Membro pode adotar, de forma compatível com as outras disposições deste Acordo, medidas apropriadas para evitar ou controlar tais práticas, que podem incluir, por exemplo, condições de cessão exclusiva, condições que impeçam impugnações da validade e pacotes de licenças coercitivas, à luz das leis e regulamentos pertinentes desse Membro.
} 


\title{
Personalidade Acadêmica Homenageada:
}

Raymundo Juliano Feitosa (Universidade Federal do Rio Grande do Norte - UFRN)

interpretação econômica voltada à manutenção da concorrência sadia e desenvolvimento tecnológico que, em muitos casos, vai de encontro com o comprimento da função social do contrato ${ }^{56}$.

Outro aspecto polêmico está na capacidade que o INPI tem de adiantar ou retardar o processo de averbação de um contrato de tecnologia em razão do interesse econômico governamental:

\begin{abstract}
Apesar de o INPI possuir um determinado protocolo a seguir para averbar contratos, esta autarquia poderá optar por acelerar ou atrasar sua decisão final em razão da balança comercial brasileira. Ou seja, a averbação de um contrato será mais rápida ou mais lenta em razão da intenção governamental de permitir ou não determinadas remessas de valores para o exterior ${ }^{57}$.
\end{abstract}

Ocorre que, tais atribuições do Poder Público, não são completamente teratológicas. Com a promulgação da Constituição de 1988 houve uma preocupação com a função social da propriedade cuja finalidade era evitar que sua utilização se voltasse ao egoísmo do proprietário e prejudicasse a sua destinação econômica e social ${ }^{58}$, não excluindo desta concepção a propriedade imaterial que ficou resguardada no artigo 50, inciso XXIX ${ }^{59}$. Assim, protegeu-se a criação e a utilização pelo Autor do seu invento da mesma forma que protegeu a coletividade na medida em que restringiu a utilização desta invenção em detrimento do interesse social, desenvolvimento tecnológico e econômico do Brasil.

O direito de propriedade mal utilizado ou utilizado sem função social ou com finalidade meramente emulativa constitui abuso de direito ${ }^{60} \mathrm{e}$, portanto, o Estado criou

\footnotetext{
${ }^{56}$ BARCELLOS, Milton Lucídio Leão. Revisitando os contratos envolvendo direitos de propriedade industrial: a função social, o efeito relativo, a regulação e a autonomia privada, in ADOLFO, Luiz Gonzaga Silva et al (Org.). Propriedade Intelectual em Perspectiva. Rio de Janeiro: Lumen Juris, 2008, p. 336-337.

${ }^{57}$ PEREIRA, Catia Correa. Transferências internacionais de tecnologia: uma perspectiva brasileira in RODRIGUES JUNIOR, Edson Beas et al (Org.). Propriedade Intelectual: Novos paradigmas internacionais, conflitos e desafios. Rio de Janeiro: Elsevier, 2007, p. 553

${ }^{58}$ VIANA, Marco Aurélio. Comentários ao Novo Código Civil, in ADOLFO, Luiz Gonzaga Silva et al (Org.). Propriedade Intelectual em Perspectiva. Rio de Janeiro: Lumen Juris, 2008, p. 336-337.

59 Constituição Federal, artigo 5º, inciso XXIX - "a lei assegurará aos autores de inventos industriais privilégio temporário para sua utilização, bem como proteção às criações industriais, à propriedade das marcas, aos nomes de empresas e a outros signos distintivos, tendo em vista o interesse social e o desenvolvimento tecnológico e econômico do País".

60 VENOSA, Sílvio de Salvo. Direito Civil - Direitos Reais, 3 ed. São Paulo: Atlas, 2003, v. 5, p. 154
} 


\section{Personalidade Acadêmica Homenageada:}

Raymundo Juliano Feitosa (Universidade Federal do Rio Grande do Norte - UFRN)

mecanismos capazes de analisar a tecnologia que é objeto que uma transação jurídica a fim de garantir o cumprimento de sua função social, muito embora isso crie diversas discussões no âmbito acadêmico acerca da existência de um desequilíbrio entre a liberdade de contratar, o poder público e a função social do contrato de transferência de tecnologia.

\section{CONCLUSÃO}

Não há como dissociar o homem da tecnologia e tal assertiva não permeia discussões, pois é inerente da condição humana o emprego mental, ou seja, o exercício racional crítico, para o manuseio e criação de novas ferramentas que possibilitem tornar o convívio humano mais versátil e confortável. Obviamente que com o passar do tempo esse emprego mental tornou-se não só necessário para o incremento da vida em sociedade como também para desenvolvimento e aprimoramento dos próprios meios de produção e fortalecimento do Estado.

Tanto é que a própria Constituição Federal brasileira dispõe expressamente em seu artigo 218 que "o Estado promoverá e incentivará o desenvolvimento científico, a pesquisa, a capacitação científica e tecnológica e a inovação". Em seguida, no parágrafo primeiro do referido artigo dispõe que "a pesquisa científica básica e tecnológica receberá tratamento prioritário do Estado, tendo em vista o bem público e o progresso da ciência, tecnologia e inovação". E estabelece ainda no parágrafo segundo do mesmo artigo que "a pesquisa tecnológica voltar-se-á preponderantemente para a solução dos problemas brasileiros e para o desenvolvimento do sistema produtivo nacional e regional".

Nesta toada de atuação do Estado no domínio econômico e sua inequívoca importância e vitalidade para a manutenção do sistema capitalista e desenvolvimento econômico, criaram-se mecanismos jurídicos capazes de promoverem a livre circulação da tecnologia de forma nacional e internacional. Essa circulação permite não somente ao particular extrapolar as barreiras brasileiras, aumentando seu lucro e 


\section{Personalidade Acadêmica Homenageada:}

Raymundo Juliano Feitosa (Universidade Federal do Rio Grande do Norte - UFRN)

aprimorando seus inventos, como também amplia as possibilidades de avanço estatal na economia.

Dentre os mecanismos jurídicos capazes de possibilitar a circulação da tecnologia, o presente ensaio deu ênfase exclusivamente aos aspectos que envolvem os contratos de transferência de tecnologia e know-how, delimitando lições propedêuticas acerca da teoria geral dos contratos, bem como as características peculiares de cada instrumento jurídico em referência. Tudo isso para se atingir o ponto central da presente discussão que se perfaz na interferência do poder público frente a liberdade de contratar dos particulares

A discussão em cotejo não é inédita e também não se esgotará no presente estudo. A interferência do Estado na regulamentação das questões particulares, principalmente quanto estas envolvem as temáticas do desenvolvimento tecnológico, sempre será questionado. Todavia, o que se propôs aclarar é que, muito embora gere certa indignação aos particulares quando da sua submissão as diretrizes governamentais, as imposições estatais para regulamentação e gerenciamento das tecnologias que são desenvolvidas no país não são teratológicas e arbitrárias.

Como visto, o propósito de implementar políticas de cunho econômico, neste caso específico tratou-se das diretrizes do INPI acerca da inevitabilidade de averbação dos contratos de transferência de tecnologia, perpassa pela necessidade de agrupar objetivos institucionais destinados à melhoria do setor e proteção do desenvolvimento econômico e tecnológico.

Tal melhoria engloba, não somente a defesa nacional, como também garante a função social do direito de propriedade, pois ainda que imaterial, o possuidor da tecnologia tem proteção perante terceiros e, portanto, o Estado instituiu mecanismos capazes de assegurar o cumprimento de sua função social, muito embora isso impulsione discussões sobre eventual desequilíbrio entre a liberdade de contratar, o poder público e a função social do contrato de transferência de tecnologia.

Provou-se no decorrer da história da humanidade que a teoria de intervenção mínima estatal caiu por terra já no século XIX e que o Estado não pode ser silente aos desenvolvimentos apresentados e os riscos que tal avanço pode acarretar na sociedade. O INPI e suas diretrizes, bem como os tratados internacionais e legislação 
Personalidade Acadêmica Homenageada:

Raymundo Juliano Feitosa (Universidade Federal do Rio Grande do Norte - UFRN)

correlata são a materialização de proteção que o Estado encontrou frente a contemporaneidade e o galopante desenvolvimento científico.

\section{REFERÊNCIAS}

ADOLFO, Luiz Gonzaga Silva et al (Org.). Propriedade Intelectual em Perspectiva. Rio de Janeiro: Lumen Juris, 2008.

ASSAFIM, João Marcelo de Lima. A transferência de Tecnologia no Brasil, 2.ed., Rio de Janeiro: Editora Lumen Juris, 2010.

AZEVEDO, Álvaro Villaça. Teoria geral dos contratos típicos e atípicos, 3. ed., São Paulo: Atlas, 2009.

BARCELLOS, Milton Lucídio Leão. Revisitando os contratos envolvendo direitos de propriedade industrial: a função social, o efeito relativo, a regulação e a autonomia privada, in ADOLFO, Luiz Gonzaga Silva et al (Org.). Propriedade Intelectual em Perspectiva. Rio de Janeiro: Lumen Juris, 2008, p. 336-337.

BLASI, Gabriel Di. A Propriedade Industrial, 3.ed., Rio de Janeiro: Editora Forense, 2010.

BRASIL. Código civil - Lei nº 10.406, de 10 de janeiro de 2002.

Constituição dos Estados Unidos do Brasil. Rio de Janeiro: Congresso Nacional, 1934.

Instituto Nacional da Propriedade Industrial.

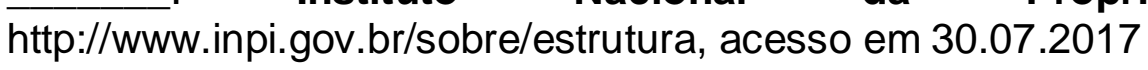

Instrução Normativa n. 16/2013 emanada pelo Ministério Do Desenvolvimento, Indústria e Comércio Exterior Instituto Nacional da Propriedade Industrial Disponível em: <http://www.inpi.gov.br/legislacao1/instrucao_normativa_16-2013.pdf>. Acesso em:.11 de jul. 2017.

. Lei n. 10.168 de 29.12.2000, alterada pela Lei n. 10.332 de 19.12.2001.

. Lei no 5.648, de 11 de dezembro de 1970. Disponível em: <http://www.planalto.gov.br/ccivil_03/Leis/L5648.htm>. Acesso em 30. jun. 2017

Decreto no 1.355, de 30 de dezembro de 1994. Disponível em http://www.inpi.gov.br/legislacao-1/27-trips-portugues1.pdf, acesso em 12 de jul. 2017 
Personalidade Acadêmica Homenageada:

Raymundo Juliano Feitosa (Universidade Federal do Rio Grande do Norte - UFRN)

CARVALHO, Carlos Eduardo Neves de. Contratos de know-how (fornecimento de tecnologia), In Revista da ABPI, n. 128, jan/fev 2014.

CHINEN, Akira. Know-how e Propriedade Industrial, São Paulo: Editora Oliveira Mendes, 1997.

CORREA, Daniel Rocha. Contratos de transferência de tecnologia: controle de práticas abusivas e cláusulas restritivas. Belo Horizonte: Movimento Editorial da Faculdade de Direito da UFMG, 2005, p. 96;

DINIZ, Maria Helena. Direito Civil Brasileiro, v. 3. São Paulo: Saraiva, 2002, p. 23. FEKETE, Elizabeth Kasznar. O regime jurídico do segredo de indústria e comércio no direito brasileiro. Rio de Janeiro: Forense, 2003.

FLORES, Cesar. Segredo industrial e o know-how: aspectos jurídicos internacionais. Rio de Janeiro: Editora Lumen Juris, 2008.

FONSECA, Pedro Cezar Dutra. Do progresso ao desenvolvimento: Vargas na Primeira República. In: BASTOS, Pedro Paulo Zahluth; FONSECA, Pedro Cezar Dutra (Orgs). A Era Vargas: desenvolvimentismo, economia e sociedade. São Paulo: Editora Unesp, 2012.

FRANCO, Karin Klempp. A regulação da contratação internacional de transferência de tecnologia - perspectiva do direito de propriedade industrial, das normas cambiais e tributárias e do direito concorrencial. 2010.242 f. Tese (Doutorado) - Curso de Direito, Direito Comercial, Faculdade de Direito da Universidade de São Paulo, São Paulo, 2010. Disponível em:

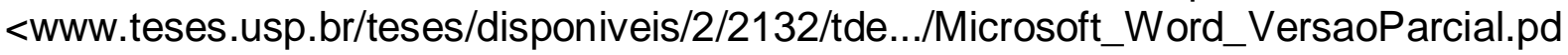
f>. Acesso em: 10 jul. 2017.

GONÇALVES, Carlos Roberto. Direito Civil brasileiro 3 - Contratos e atos unilaterais, 13. Ed., São Paulo: Saraiva, 2015.

KEYNES, John Maynard. As conseqüências econômicas da paz. São Paulo: Imprensa Oficial do Estado, 2002.

KNIGHT, Frank Hyneman. Risk, Uncertainty and Profit. Washington, DC: Beard Books, 2002, p. 233, apud MAZZUCATO, Mariana. O Estado empreendedor: desmascarando o mito do setor público vs. Setor privado = The Entrepreneurial State: Debunking Public vs. Private Sector Myths; tradução Elvira Serapicos. 1.ed. São Paulo: Portfolio-Penguin, 2014.

MAZZUCATO, Mariana. O Estado empreendedor: desmascarando o mito do setor público vs. Setor privado $=$ The Entrepreneurial State: Debunking Public vs. Private Sector Myths; tradução Elvira Serapicos. 1.ed. São Paulo: Portfolio-Penguin, 2014. 
Personalidade Acadêmica Homenageada:

Raymundo Juliano Feitosa (Universidade Federal do Rio Grande do Norte - UFRN)

NUSDEO, Fábio. Curso de Economia: introdução ao Direito Econômico. 4 ed. rev. e atual. São Paulo: Editora RT, 2005.

PEREIRA, Catia Correa. Transferências internacionais de tecnologia: uma perspectiva brasileira in RODRIGUES JUNIOR, Edson Beas et al (Org.). Propriedade Intelectual: Novos paradigmas internacionais, conflitos e desafios. Rio de Janeiro: Elsevier, 2007.

PRADO, Maurício Curvelo de Almeida. Contrato Internacional de Transferência de Tecnologia patente e know-how, Porto Alegre: Livraria do Advogado, 1997.

ROBINSON, Joan. The Economics of Imperfect Competition. Londres: Macmillan, 1933.

RODRIGUES JUNIOR, Edson Beas et al (Org.). Propriedade Intelectual: Novos paradigmas internacionais, conflitos e desafios. Rio de Janeiro: Elsevier, 2007.

SANTOS, Nivaldo dos. Instrumentos contratuais de gestão da propriedade intelectual, Goiânia: Ed. De UCG, 2007.

SCHUMPETER, Joseph Alois. Economic Theory and Entrepreneurial History. Change and the Entrepreneur: Postulates and the Patterns for Entrepreneurial History. Research Center in Entrepreneurial History, Harvard University. Cambridge, MA: Harvard University Press, 1949.

SOUZA, Washington Peluso Albino de. Primeiras linhas de direito econômico. 3.ed. São Paulo: LTr, 1994, p. 381/384; TAVARES, André Ramos. Ciência e tecnologia na Constituição, Revista de Informação Legislativa, no 175, jul./set. 2007, p. 7/8, apud BERCOVICI, Gilberto; SIQUEIRA NETO, José Francisco; Direito e Inovação Tecnológica. In: SCALQUETTE, Ana Cláudia S. (coord.); SIQUEIRA NETO, José Francisco (coord.); PINTO, Felipe Chiarello de Souza (org.); BAGNOLI, Vicente (org.). 60 desafios do direito: economia, direito e desenvolvimento. São Paulo: Atlas, 2013.

VENOSA, Sílvio de Salvo. Direito Civil - Direitos Reais, 3 ed. São Paulo: Atlas, 2003.

Direito civil: teoria geral das obrigações e teoria geral dos contratos, $\mathrm{V}$. 2. 14. ed., São Paulo: Atlas, 2014.

VIANA, Marco Aurélio. Comentários ao Novo Código Civil, in ADOLFO, Luiz Gonzaga Silva et al (Org.). Propriedade Intelectual em Perspectiva. Rio de Janeiro: Lumen Juris, 2008.

World Intellectual Property Organization. Standing Committee on the Law of Patents, Transfer of Technology, Genebra, 2010, disponível em: http://www.wipo.int/edocs/mdocs/scp/en/scp_17/scp_14_4_rev_2.pdf, acesso em 20.06.2017. 